\title{
Investigating treatment satisfaction and progress for offenders referred to community-based drug addiction treatment
}

\author{
Yang Yang ${ }^{1 *}$, Julie Gray ${ }^{2}$, Jennifer Pankow ${ }^{2}$, Patrick M Flynn², Kevin Knight ${ }^{2}$ \\ From 2014 Addiction Health Services Research (AHSR) Conference \\ Boston, MA, USA. 15-17 October 2014
}

\section{Background}

The current study used a multilevel modeling technique to examine the influence of client-level factors and counselor-level variance on treatment satisfaction and progress for offenders referred to community-based drug addiction treatment.

\section{Materials and methods}

The sample included 90 male participants (64 of which completed follow-up) and seven counselor participants (i.e., four females and three males) from communitybased treatment in a Midwestern metropolitan area. Hierarchical linear modeling was conducted to examine the influence of victimization and violence history, psychiatric disorders (i.e., anxiety, depression), social functioning (i.e., social support, self-esteem), drug use severity, and treatment motivation on treatment satisfaction and progress after controlling for counselor-level variances. Hierarchical linear modeling also was employed to test the mediation of treatment satisfaction on the relationship between client-level factors and treatment progress.

\section{Results}

Results indicated that higher levels of anxiety and depression were associated with a lower level of treatment satisfaction, and more social support was associated with increased satisfaction. Despite the non-significant relationship between treatment motivation and satisfaction, the influence of treatment motivation on treatment satisfaction was different across counselors. With regard to treatment

\footnotetext{
* Correspondence: yxy5019@louisiana.edu

'Department of Psychology, University of Louisiana at Lafayette, Lafayette, LA, 70504, USA

Full list of author information is available at the end of the article
}

progress, higher levels of depression predicted a decrease in progress, whereas more social support and treatment motivation were associated with an increased amount of treatment progress. Treatment satisfaction mediated the relationship of depression and social support with treatment progress, whereby a lower level of depression and more social support were associated with a higher level of treatment satisfaction, which in turn predicted a greater amount of client self-reported treatment progress.

\section{Conclusions and implications}

The findings collectively underscore the importance of integrated interventions, social support, treatment motivation, and satisfaction on treatment outcome. Clinically, these findings emphasize the importance of: 1 ) incorporating psychological interventions into substance use treatment plans; 2) providing social support and increasing treatment motivation; and 3) enhancing treatment satisfaction in an effort to improve treatment outcome.

\section{Acknowledgements \\ This study was funded by a grant to Texas Christian University (5U01DA016190; K. Knight, Principal Investigator) from the National Institute on Drug Abuse, the National Institutes of Health, with support from the Center for Substance Abuse Treatment of the Substance Abuse and Mental Health Services Administration, the Centers for Disease Control and \\ Prevention, the National Institute on Alcohol Abuse and Alcoholism (all part of the U.S. Department of Health and Human Services); and from the Bureau of Justice Assistance of the U.S. Department of Justice. The content is solely the responsibility of the authors and does not necessarily represent the official views of the funding agencies.}

\section{Authors' details}

${ }^{1}$ Department of Psychology, University of Louisiana at Lafayette, Lafayette, LA, 70504, USA. ${ }^{2}$ Institute of Behavioral Research, Texas Christian University, Fort Worth, TX, 76109, USA. 
Cite this article as: Yang et al:: Investigating treatment satisfaction and progress for offenders referred to community-based drug addiction treatment. Addiction Science \& Clinical Practice 2015 10(Suppl 1):A75.

Submit your next manuscript to BioMed Central and take full advantage of:

- Convenient online submission

- Thorough peer review

- No space constraints or color figure charges

- Immediate publication on acceptance

- Inclusion in PubMed, CAS, Scopus and Google Scholar

- Research which is freely available for redistribution

Submit your manuscript at www.biomedcentral.com/submit
Ciomed Central 